28 Rohricht F. Body-Oriented Psychotherapy in Mental Illness: A Manual for Research and Practice. Hogrefe, 2000.

29 Röhricht F. Body oriented psychotherapy. The state of the art in empirical research and evidence-based practice: a clinical perspective. Body Mov Dance Psychother 2009; 4: 135-56.

30 Röhricht F, Papadopoulos N, Priebe S. An exploratory randomized controlled trial of body psychotherapy for patients with chronic depression. J Affect Disord 2013; 151: 85-91.

31 Gold C, Solli HP, Krüger V, Lie SA. Dose-response relationship in music therapy for people with serious mental disorders: systematic review and meta-analysis. Clinical Psychol Rev 2009; 29: 193-207.

32 Newham E. Pilates Union UK: Comprehensive Matwork Manual. Pilates Union UK, 2010.

33 Angrist JD, Imbens GW, Rubin DB. Identification of causal effects using instrumental variables. J Am Stat Assoc 1996; 91: 444-55.

34 Adams M, Caldwell K, Atkins L, Quin R. Pilates and mindfulness: a qualitative study. J Dance Educ 2012; 12: 123-30.
35 Khoury B, Lecomte T, Gaudiano A, Paquin K. Mindfulness interventions for psychosis: a meta-analysis. Schizophr Res 2013; 150: 176-84.

36 Savill $\mathrm{M}$, Banks $\mathrm{C}$, Khanom $\mathrm{H}$, Priebe S. Do negative symptoms of schizophrenia change over time? A meta-analysis of longitudinal data. Psychol Med 2015; 45: 1613-27.

37 Ren J, Xia J. Dance therapy for schizophrenia. Cochrane Database Syst Rev 2013; 10: CD006868.

38 Mössler K, Chen X, Heldal TO, Gold C. Music therapy for people with schizophrenia and schizophrenia-like disorders. Cochrane Database Syst Rev 2011; 12: CD004025.

39 Blanchard JJ, Kring AM, Horan WP, Gur R. Toward the next generation of negative symptom assessments: the collaboration to advance negative symptom assessment in schizophrenia. Schizophrenia Bull 2011; 37: 291-9.

40 Blanchard JJ, Cohen AS. The structure of negative symptoms within schizophrenia: implications for assessment. Schizophr Bull 2006; 32: 238-45.

\title{
On Anti-Oedipus (1972) by Gilles Deleuze and Félix Guattari
}

\section{George Huntington}

Up until 1972, the last word on psychoanalysis came from Lacan. However, that was to change when a philosopher and a psychotherapist, Gilles Deleuze and Félix Guattari (both also French), began to publish their seminal work re-examining psychoanalysis, entitled Capitalism and Schizophrenia. The two books arising from this effort, Anti-Oedipus and A Thousand Plateaus result from a fusion and critique of Freud and Marx with the view to establishing a new method of critical psychoanalysis: schizoanalysis. These works became a staple of French critical theory and post-structuralism in the 1970s, a position they still occupy today. The text of Anti-Oedipus (so named for its opposition to Freud) was later translated by Robert Hurley in 1983 and brought to a wider audience.

Deleuze and Guattari were not the first to explore the relation of society and the individual with reference to mental health. The first ground in this area was broken by French philosopher Michel Foucault in his 1961 work, Madness and Civilisation which was referenced heavily on both Anti-Oedipus and its other half. The authors must be pleased then with Foucault's seal of approval, as now many English editions carry a foreword he penned. However, Capitalism and Schizophrenia focused less on views of mental illness espoused by medieval and Enlightenment cultures and more on post-industrial revolution opinions, particularly within a Marxist framework. Although this method of interpreting the historical catalogue is nowadays banal, at the time the two were trailblazers set to inspire a generation of sociologists as well as psychoanalysts.

It is difficult to summarise a central goal and single take-home message of the text. If there is one for the psychiatric discipline, it is this: that society has an Ego and psychoanalysis is just another power structure within society; a paternalistic church (a common critique extended to psychiatry). Thus, if therapists are to truly make headway with their patients they must approach them as equals. However, this concentration on the authors' 'materialist' psychiatry neglects their introduction of the post-structuralist concept of 'body without organs'. Simply put, in an assemblage of working parts which are capable of functioning individually, there is a potential which is greater than the sum of its parts. An extreme example of this is given as the worldview of a patient with schizophrenia: inwardly looking, 'deep' extremes and branching ideals.

Anti-Oedipus is a challenging read, even if one is able to overcome the 'rhizome' structure; a non-hierarchical method of writing. It includes bounteous references sweeping the board of French and international literature; Camus, Derrida, Kafka, Ginsberg and Nietzsche (particularly The Anti-Christ). These allusions are not just limited to the bibliophiles' world as the two authors also give examples ranging from early cinema and popular music to geology and embryology to support their new pseudo-anarchist philosophy. Drawing from such a diverse set of resources may appear grandiose perhaps, but when such large Western ideas as psychology and economics are being evaluated as a whole this seems necessary. Though it is concerning that the arguments are made from epistemology rather than any evidence from a therapeutic framework.

From a clinical standpoint it is less instructive. The 'schizoanalysis' first introduced here is better suited for critical practice than for any therapeutic end. The 'schizophrenia' discussed throughout bears little resemblance to any entity encountered beyond the armchair. However, the recent emergence of patient-centred care and user-led research can be related to the egalitarian ideas initially presented by Deleuze and Guattari. Parity of esteem comes from realising patients as equals and accommodating their needs and expectations into services provided. Modern practice is in process of accepting this. However, when the authors were writing, care was paternalistic and rigid. Perhaps this is why they are critical of psychiatry. It is interesting to note how times have changed. 